\title{
Sensory-motor training targeting motor dysfunction and muscle weakness in long-term care elderly combined with motivational strategies: a single blind randomized controlled study
}

\author{
Slavko Rogan ${ }^{1,3}$, Lorenz Radlinger ${ }^{1}$, Heiner Baur ${ }^{1}$, Dietmar Schmidtbleicher ${ }^{2}$, Rob A. de Bie ${ }^{3,4}$
} and Eling D. de Bruin $3,4,5^{*}$

\begin{abstract}
Background: This study evaluated the effects of a combined innovative training regime consisting of stochastic resonance whole-body vibration (SR-WBV) and a dance video game (DVG) on physical performance and muscle strength in long-term-care dwelling elderly.

Methods: Thirthy long-term-care elderly were randomly allocated to an intervention group (IG; $n=16)$ receiving combined SR-WBV training and DVG, or a sham group (SG; $n=14)$. IG performed five sets one minute of SR-WBV, with one minute rest between sets (base frequency $3 \mathrm{~Hz}$ up to $6 \mathrm{~Hz}$, Noise 4) during the first five weeks on three days per week. From week five to eight a DVG was added to SR-WBV for IG on three days per week. SG performed a five-set SR-WBV program (1 Hz, Noise 1) lasting five times one minute, with one minute rest in between, three days a week. From week five to eight stepping exercises on a trampoline were added on three days per week. Primary outcome: Short physical performance battery (SPPB). Secondary outcome: isometric maximal voluntary contraction (IMVC), and sub phases of IMVC (Fsub), isometric rate of force development (IRFD) and sub time phases of IRFD (IRFDsub) were measured at baseline, after four and eight weeks. ANOVA with repeated measures was used for analyses of time and interaction effects and MANOVA determined between group intervention effects.
\end{abstract}

Results: Between group effects revealed significant effects on the SPPB primary outcome after four weeks $F(1,27)=6.17$; $p=0.02)$ and after eight weeks $F(1,27)=11.8 ; p=0.002)$. Secondary muscle function related outcome showed significant between group effects in IG on IRFD, Fsub 30 ms, 100 ms, 200 ms and IRFDsub 0-30 ms, 0-50 ms, 0-100 ms and 100-200 ms compared to SG (all $p<0.05$ ).

Conclusions: Eight weeks SR-WBV and DVG intervention improved lower extremity physical function and muscle strength compared to a sham intervention in long-term-care elderly. SR-WBV and DVG seems to be effective as a training regime for skilling up in long-term-care elderly.

Keywords: Sensory-motor training, Motor dysfunction, Muscle weakness, Long-term care, Motivational strategies

\footnotetext{
* Correspondence: eling.debruin@hest.ethz.ch

${ }^{3}$ Department of Epidemiology, Maastricht University, CAPHRI School for

Public Health and Primary Care, Maastricht, The Netherlands

${ }^{4}$ Centre for Evidence Based Physiotherapy, Maastricht University, PO Box

6166200, MD, Maastricht, The Netherlands

Full list of author information is available at the end of the article
} 


\section{Background}

'The competence of an individual to have the physiological capacity to perform normal everyday activities safely and independently without undue fatigue' [1] signifies the functional abilities of an individual. Disability, defined as difficulty or dependency in the execution of the activities of daily living, is associated with increased healthcare utilization and related costs [2]. Disability in frail older people is considered a public health problem [3] in which prevention has to be considered a priority for research and clinical practice [4]. Physical activity (PA) for the elderly is one of the major elements for general health prevention [5]; therefore inactive or sedentary elderly should increase their PA [6]. Despite the known benefits of PA, residents living in long-term care (LTC) are relatively sedentary $[7,8]$.

The loss of muscle mass and strength with age, coined sarcopenia, is recognized as a major cause of disability and morbidity in the elderly [9]. Sarcopenia describes the progressive decline in skeletal muscle mass and function (strength or performance) with advancing age [10]. However, recent studies demonstrated that muscle atrophy is a relatively small contributor to the loss of muscle strength [11-13]. Changes in neurologic function and/or the intrinsic force-generating properties of skeletal muscle are recently proposed to be responsible for muscle weakness and motor dysfunction in the elderly $[11,14-18]$. Dynapenia has been used to coin this ageassociated loss of muscle strength and power with its significant clinical consequences; e.g., the increased risk for functional limitations, disability, and mortality. Dynapenia encompasses broader aspects of skeletal muscle performance, and so includes strength (i.e., maximal voluntary force) and/or mechanical power (a product of force - time velocity) [19] together with aspects of neurological functioning $[20,21]$.

Both neurologic and skeletal muscle properties are necessary for optimal muscle force production and control $[16,17,22]$. The nervous system's ability to fully activate a skeletal muscle voluntarily for example seems to be impaired in individuals with dynapenia [23]. Furthermore, poor sensorimotor nerve function independently predicts mobility disability [24]. Targeting neural structures through exercise is, therefore, considered important in influencing muscle strength in elderly [25].

Efficient movement function and the maintenance of balance function during dynamic tasks; e.g., during walking, are more complex than merely adequate force production from the muscles [26]. For whole body movements it is important to precisely coordinate muscle actions. This requires sensory, biomechanical and motor-processing strategies along with learned responses from previous experiences and anticipation of change $[27,28]$. Adequately combining three levels of motor control (spinal reflex, brain stem balance, and cognitive programming) produces appropriate muscle responses [29]. So, from these results, it can be hypothesised that when focusing on these three levels of motor control in a training program there will be improvements in muscle recruitment and timing and, hence, physical functioning and muscle strength.

Stochastic resonance (SR) is a phenomenon in nonlinear systems characterized by a response increase of the system induced by a particular level of input noise [30, 31]. One of the first studies applying noise in humans revealed increased sensitivity to detect sub-threshold tactile stimuli as an effect to such an intervention [32]. Cordo and colleagues [33] were among the first to demonstrate that the application of noise on human muscle spindle receptors improved afferents sensitivity in the human motor system and suggested, based on their results, that a stochastic-resonance based technique could be applied in clinical settings to individuals with elevated cutaneous thresholds; e.g., to older adults [33]. First evidence that mechanical noise applied to the feet via vibrating insoles improved balance in standing position stems from Pripatla et al. [34] and Collins and coworkers [35]. Systematic reviews concluded that, compared to more demanding interventions, whole-body vibration (WBV) as a sensorimotor training might be a safer and less fatiguing type of exercise [36] with a beneficial effect on movement skills [37] and muscle strength [38]. Stochastic resonance whole-body vibration (SRWBV) has been described as stimulating sensorimotor processes [31, 39] with a positive effect on muscle functional strength [38]. The SR-WBV stimulus triggers muscle spindles and, thereby, improves the functionality of the muscle-nerve system [40] and adjusts afferent and efferent signals which, in turn, are leading to "training" effects for the sensorimotor system [41]. Muscle strength increase following SR-WBV is mainly attributed to neural adaptation bringing on improvements in interand intra-muscular coordination [42]. See [43] for an overview. Virtual reality training techniques may be used to incorporate cognitive programming elements into exercise [44] and could, hence, also be part of a training program for elderly [45]. Pilot trials with long term care dwelling elderly showed beneficial effects on physical performance for those adhering to an SR-WBV intervention, however, the program requires modifications that target improved compliance with the intervention [46]. Interventions performed with frail individuals often suffer from low adherence rates and are, therefore, advised to specifically include support and motivation strategies, as well as giving assistance to individuals to develop both goals and the strategies to achieve these [47, 48].

The aim of this study was to assess the effects of a sensorimotor training program with SR-WBV \& Virtual 
Reality Training that was accompanied with motivational instructions in LTC elderly on lower extremity physical function and leg muscle properties. We hypothesised that an intervention program that targets motor control will effect on physical functioning and muscle strength of LTC elderly.

\section{Methods}

\section{Design}

This study follows the publication guideline of CONSORT [49], in the form of a randomised controlled trial with blinded LTC dwelling elderly individuals, randomly divided over intervention (IG) and sham control (SG) groups. The assessor and supervisors were not blinded. Measurements were carried out at baseline (BASE), after four weeks $(4 \mathrm{~W})$ and after eight weeks $(8 \mathrm{~W})$ of training. Data were collected and analysed for participants that completed $90 \%$ of the scheduled training sessions. Figure 1 presents the study flow.

\section{Participants}

Inclusion criteria was: age over 65 years, able to stand with or without walking aids, living in the Canton of Berne, being classified as Resident Assessment Instrument (RAI) ${ }^{1}$ performance level $>0$, having a score $\geq 18$ in the MiniMental Status Examination (MMSE) Test and $\leq 6$ points on the Short Physical Performance Battery. Scoring $\leq 6$ points on the Short Physical Performance Battery relates to poor physical performance and is a risk indicator for sarcopenia [50]. Exclusion criteria were: visual disturban$\mathrm{ces}^{\mathrm{b}}$, lower or upper leg prosthesis, acute joint disease, acute thrombosis, acute fractures, acute infections, acute tissue damage, acute surgical scars or alcohol abuse. The sampling frame of LTC elderly fulfilling the inclusion/exclusion criteria and receiving information about the study comprised 40 individuals (Table 1). Thirty-one LTC elderly agreed to participate and were reached through personal interview and/or public information events.

\section{Randomisation}

An independent research assistant performed randomisation, using a random Microsoft Excel 2010 table. The participants were randomly assigned to either IG or SG by means of sealed opaque envelopes distributed after the completion of all baseline assessments. Prior to the start of the intervention, written informed consent was obtained from all participants following Ethical Committee approval (Canton Berne; Registration number 147/12).

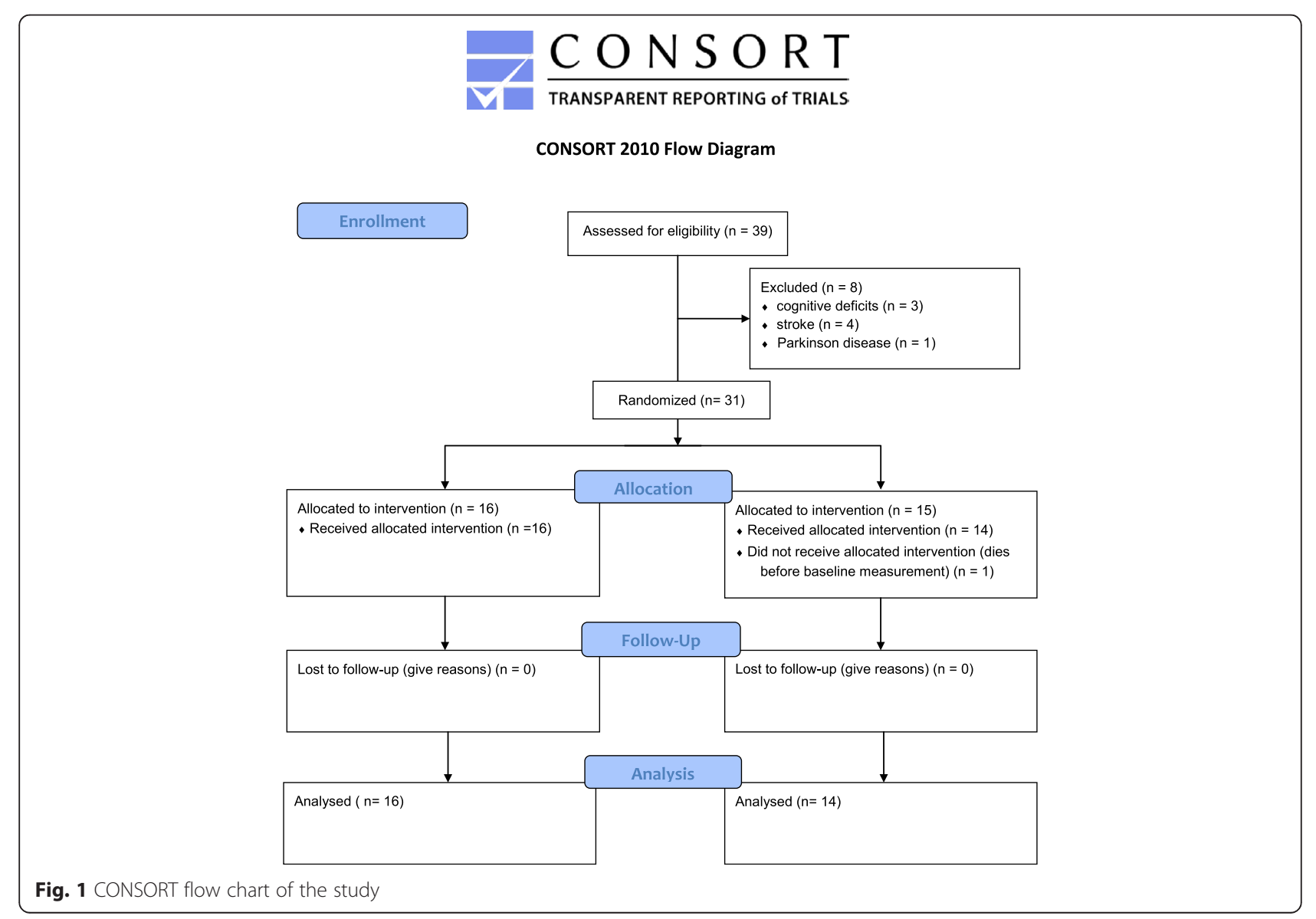


Table 1 Demographic characteristics at baseline (mean \pm SD)

\begin{tabular}{llll}
\hline & IG & SG & $p$ \\
\hline Sample & 16 & 14 & \\
Sex (F/M) & $10 / 6$ & $10 / 4$ & \\
Age (years) & $90.4 \pm 6.9$ & $87.2 \pm 5.0$ & 0.156 \\
Age (range) & $77-100$ & $79-97$ & \\
Height (m) & $1.63 \pm 0.1$ & $1.58 \pm 0.1$ & 0.256 \\
Weight (kg) & $66.9 \pm 14.2$ & $67.1 \pm 20.8$ & 0.969 \\
BMl (kg/cm ${ }^{2}$ ) & $25.1 \pm 4.8$ & $26.5 \pm 6.8$ & 0.542 \\
\hline
\end{tabular}

IG intervention group, SG sham group, $F$ female, $M$ male, BMI Body mass index, SPPB Short Physical Performance Battery

The study protocol was registered at U.S. National Institute of Health (NCT02102919; https://clinicaltrials.gov/ ct2/show/NCT02102919).

\section{Intervention protocol}

All participants were familiarised with the SR-WBV and the Dance Video Game (DVG) device one week prior to the intervention period with the aim to reduce anxiety. In the DVG session a tutorial sequence was provided to ensure understanding of the task.

\section{Stochastic resonance whole-body vibration}

Participants were exposed to SR-WBV using a Zeptor med $^{\bullet}$ device (Frei Swiss AG, Zurich, Switzerland) while standing freely on both legs wearing no shoes with slight flexion of the hips, knees and ankle joints. A purpose made seat was used to allow participants to sit down during the one-minute breaks. Each intervention consisted of five one-minute vibration periods with a one-minute break between sets. The intervention took place on three days a week, over a period of eight weeks. IG vibrated with a basic frequency of $3 \mathrm{~Hz}$ and noise level 4 since a previous study showed this to be a good starting level for our target population [51]. To ensure progression of the exercise, the basic frequency gradually increased to $6 \mathrm{~Hz}$, depending on capabilities and feedback of the individual concerned. The amplitude was a constant $4 \mathrm{~mm}$ during the 8 weeks period. In analogy to previously described protocols [52] progression of the exercise intensity was based on participant's abilities related to maintain postural stability with decreasing base of support: from being able to stand with parallel positioned feet without holding onto the bars, the vibration frequency was increased gradually from $3 \mathrm{~Hz}$ up to $6 \mathrm{~Hz}$. From $6 \mathrm{~Hz}$, the parallel standing position changed to tandem standing and ended with this position while dynamic squat movements were performed on the vibrating plates. SG vibrated with a basic frequency of $1 \mathrm{~Hz}$ and noise level 1 with no increase of the basic frequency and no additional exercises. The $1 \mathrm{~Hz}$ frequency was expected to cause no training effect [53] as previously shown [54-56].

\section{Dance video game}

As an additional cognitive element the DG performed the dance video game after the SR-WBV exercise in every training session. The dance video game was performed on metal dance pads (TX 6000 Metal DDR Platinum Pro, $93 \mathrm{x}$ 14.7 x 109 cm, Mayflash Limited, Baoan Shenzhen, China) and with a specially designed modification of the StepMania (Version 3.9) free-ware $[44,57,58]$. The dance video game screen was projected on a white wall. A scrolling display of arrows moving upwards across the screen cued each move, and the participants were asked to execute the indicated steps (forward, backward, right, or left) when the arrows reached the fixed raster graphic at the top of the screen, and in time with different songs (32 to 137 beats per minute). For each training session, the participants performed for four songs of two to three minutes each, with a short break of $30 \mathrm{~s}$ after each song. Progression of performance was controlled through beats per minute and difficulty level and adapted based on performance of an individual.

As the levels increased, additional distracting visual cues, e.g., "bombs," were presented. Participants had to ignore these cues and keep their attention focused on the arrows. Occasionally, some arrows were drawn-out on the target locations indicating that the participants should remain for a while on the dance pad button on one leg. The arrow sequences were generated using the Dancing Monkey MATLAB script [59] and determined step error. Electronic sensors in the dance pad detected position and timing information that was then used to provide participants with real-time visual feedback.

Video game dancing (DANCE) promotes fast, rhythmic, and accurate foot movements and may improve higher cognitive processing as measured by standard neuropsychological tests $[60,61]$.

\section{Motivation strategy}

A professional exercise instructor (SR) coached the participants in both groups to enhance exercise participation and ensure that the targeted exercise frequencies and levels, sessions duration [8], and prevention of attrition [62] would be reached. The exercise instructor focused on the motivation to perform functional activities in the LTC setting [63] with the help of Motivation-Volition (MoVo) [64]. MoVo programs, where the acronym stands for "motivation" and "volition", have previously shown to be succesfull in reaching higher compliance and fewer dropout rates for exercise in in-patient rehabilitation settings [65]. In brief, MoVo intervention programs encompass the following motivational strategies: (a) clarification of personal health objectives; (b) contemplation of different actions to achieve the health objectives; (c) formation of specific goal intentions; (d) checking self-concordance of this goal intention; and (f) reflection of outcome experiences. Furthermore, MoVo puts a strong emphasis on subsequent 
volitional strategies: (a) generating implementation intentions; (b) anticipating personal barriers; (c) developing counter strategies; and (d) self-monitoring the new behavior. The specific features of MoVo are described in more detail elsewhere [64].

\section{Primary outcome}

The Short Physical Performance Battery (SPPB) [66], a standardized measure of physical performance that assesses standing balance, usual gait velocity over a 4-m course, and the time to sit down and rise from a chair five times as quickly as possible, has been recommended for use as a functional outcome measure in clinical trials in frail older persons [67]. The SPPB shows high reliability with an ICC of 0.88-0.92 [68]. SPPB scores range from 0 (lowest function) to 12 (highest function) points and can be classified as: "weak performance" for scores from 0 to 6 points, "mean performance" for 7 to 10 points, "good performance" for 11 to12 points [69]. The SPPB scale predicts institutionalization, hospital admission, mortality, and disability [66, 70, 71].

\section{Secondary outcomes}

Isometric maximal voluntary contraction (IMVC) and isometric rate of force development (IRFD) of knee extension and knee flexion were measured. The onset of force was determined at 10 Newton $(\mathrm{N})$ of each individual's forcetime curve. IMVC in $\mathrm{N}$ was determined as the maximum point on the force-time curve. Submaximal force (Fsub) values were calculated at $30,50,100$ and $200 \mathrm{~ms}$ relative to the onset of force and presented the maximum voluntary contraction values $(\mathrm{N})$ at this time point. IRFD was defined as the maximal slope of the force-time curve between onset of force and $200 \mathrm{~ms}(\mathrm{~N} / \mathrm{ms})$. Submaximal IRFD values (IRFDsub) were calculated as the mean slope of the forcetime curve $(\Delta \mathrm{F} / \Delta \mathrm{t})$ over time intervals of $0-30,0-50,0$ 100 and 100-200 ms relative to the onset of force [72]. The onset of force was $0 \mathrm{~ms}$.

A strain gauge (Sensor KM 1500S, Megatron, Munich, Germany) was used to measure the force values. The participants sat on a chair with $90^{\circ}$ knee flexion and the dynamometers were fixed above the right $(\mathrm{r})$ and left (l) ankle joint (Fig. 2). On the command "3-2-1-go!" the participants had to flex (flex) or extend (ex) each knee separately for five seconds as fast and as strongly as possible against the fixation. Details of the protocol were previously published and result in reliable measures with intraclass correlation coefficients (ICC) ranging between from 0.90 to 0.98 [73]. The analogue signal of the dynamometer was transmitted to a measurement amplifier (UMV, uk-labs, Kempen, Germany), digitalised by a 12bit A-/D-converter (Meilhaus ME-2600i, SisNova Engineering, Zug, Switzerland) with a sampling rate of $1 \mathrm{kHz}$

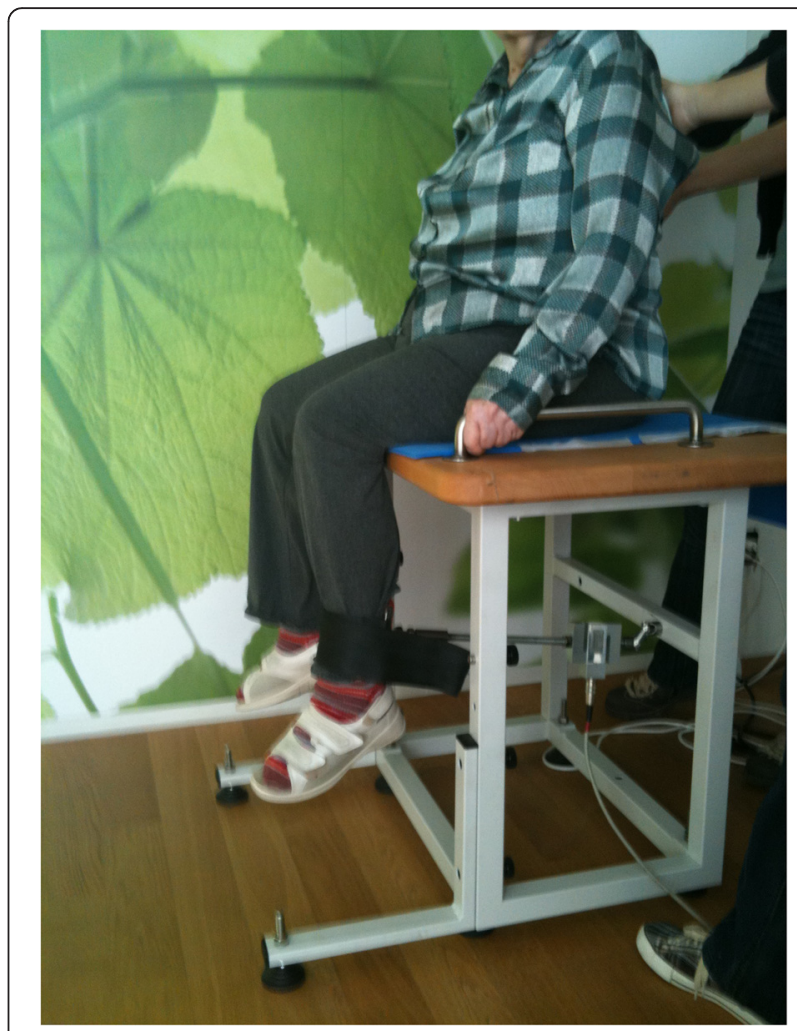

Fig. 2 Set-up for the muscle strength assessment

and analyzed with the Analogue Digital Signal processing software (ADS, uk-labs, Kempen, Germany).

\section{Data processing}

Dynamometer data was processed with a costum-made software routine (MATLAB R2013a). After low-pass filtering $\left(10 \mathrm{~Hz}, 2^{\text {nd }}\right.$ order Butterworth, forward-backward) the force-time curves were visually inspected for plausibility and to determine the time points of force onset $(10 \mathrm{~N})$. Force parameters were then calculated according [72] the respective time windows.

\section{Sample size calculation}

The primary study objective was to evaluate the effect of SR-WBV and DVG compared to sham intervention on lower extremity physical performance as assessed with the SPPB. Based on an estimated meaningful change in SPPB score of 1 point [74-76], a significance level set at $5 \%$, a power of $80 \%$ to detect differences with twosided hypothesis testing, inclusion of $N=30$ participants ( $n=15$ per group) will be needed for a two-groups prepost-test study design.

\section{Statistical analyses}

Statistical Package for Social Sciences (SPSS) 22.0 for Mac (SPSS, Inc; Chicago, Illinois) was used for all statistical analyses. An intention-to-treat analysis (ITT) was 
performed where missing data were replaced by mean values of the group to which subjects were originally allocated [77]. Kolmogorov-Smirnov test was used to assess normality of data distribution. Baseline demographic data and baseline outcome data comparing IG and SG were analyzed by unpaired students $t$-test.

A 2 (groups) x 3 (measurements) repeated measures analysis of variance (ANOVA) was carried out to test for interactions and time effects (Greenhouse-Geisser corrected). We used nonparametric Rank-Order Tests of Puri and Sen L Statistics to assess change over time where Pillai's Trace was used to calculate L [78-80].

For effect sizes (ES) assessing meaningfulness of differences within and between groups, eta-squared $\left(\eta^{2}\right)$ in ANOVA and MANOVA was used. For $\eta^{2}$, an effect size of 0.01 is considered a 'small' effect, around 0.06 a 'moderate' effect and 0.14 and above a 'large' effect [81].

\section{Results}

From the 40 LTC elderly approached, 31 agreed to participate (Fig. 1) resulting in a $77.5 \%$ recruitment rate for the sampling frame. One participant from SG died before baseline measurement and eight of the 40 initially deemed eligible were willing to participate, however, did not fulfill the inclusion criteria $(n=3$ low MMSE score; $n=4$ with recent stroke; $n=1$ with multiple sclerosis, $n=1$ with parkinson disease). Training adherence rate, expressed in \%; $[100 \div(34 \div$ Mean amount of trainings visited)] revealed a mean attendance rate of $100 \%$ (34 of 34 intervention sessions).

The participants were willing to be randomized. Neither subjective nor objective side-effects related to the used intervention were reported. At baseline, no statistically significant differences $(p<0.05)$ were found between groups.

Table 2 presents the primary and secondary outcomes at baseline. All SPPB data could be used for statistical analysis while for strength values an ITT was perfomed. The time force-curve of four participants could not be used for analysis. Fsub values and IRFDsub are listed in Additional files 1, 2, 3, 4, 5, 6, 7 and 8. At baseline no group differences were identified.

Table 2 SPPB ANOVA with repeated measurements (ranks) intergroup-by-time effects and group-by-time interaction

\begin{tabular}{lcccc}
\hline & $\begin{array}{l}\text { Pillai's trace } \\
\left(r^{2}=S_{\text {Bet }} / S_{\text {Tot }}\right)\end{array}$ & $L\left[(N-1) r^{2}\right]$ & $p$ & $E S\left(\eta^{2}\right)$ \\
\hline $\begin{array}{l}\text { SPPB Total (time } \\
\text { effects) }\end{array}$ & 0.22 & 0.30 & 0.742 & 0.22 \\
$\begin{array}{l}\text { SPPB Total } \\
\text { (interaction effects) }\end{array}$ & 0.60 & 10.20 & $0.001^{*}$ & 0.60 \\
\hline
\end{tabular}

SPPB: Short Physical Performance Battery; ${ }^{\circ}$ : significant difference $\mathrm{p}<0.05{ }^{*}$ : siginificant difference after Bonferroni adjustment $p<0.0125$; ES: effect size ( $\eta 2=.01$; small effect, $\eta 2=.06$; moderate effect, $\eta 2=.14$; large effect)
Primary outcome: short physical performance battery A significant interaction effect in SPPB; $F(1.7,48)=35.2$, $p<0.001)$ with a large ES ( $\eta 2=0.557)$ were determined in favour of IG (Table 2). The between group effect (Table 5) shows significant values after 4 weeks $\mathrm{F}(1,28=$ $6.85 ; \eta 2=0.20 ; p=0.014)$ and after 8 weeks $\mathrm{F}(1,28=$ $13.17 ; \eta 2=0.32 ; p=0.001$ ) in favour of IG.

\section{Secondary outomes: strength tests}

Tables 3, 4 and 5 summarise the intervention effects for the muscle strength related outcomes. IMVC showed significant changes over time for knee extension right and left and knee flexion right (Table 4). Post-hoc analysis revealed significant between group effects for knee flexion left $(p<0.02)$ after eight weeks of training (Table 5).

Following eight weeks of SR-WBV and DVG training, Fsub measures at $30 \mathrm{~ms}, 100 \mathrm{~ms}$ and $200 \mathrm{~ms}$ in both right and left leg flexion showed a significant between group effect $(p<0.01)$ with large ES $(>0.14)$ compared to Sham intervention (Additional files 1, 2, 3, 4, 5, 6, 7 and 8).

Table 3 shows the Greenhouse-Geisser univariate test results; a significant intragroup-by-time effect and group-bytime interaction effect following eight weeks of SR-WBV and DVG intervention on IRFD. Significant between groups effects were both seen after 4 weeks $(p<0.05)$ and 8 weeks $(p<0.05)$ in IRFD right and left leg extension and right and left leg flexion manoeuvres (Table 5).

Significant effects $(p<0.001)$ and large ES $>0.14$ in the right and left leg knee extension and knee flexion

Table 3 ANOVA with repeated measurements (ranks) intergroup-by-time effects and group-by-time interaction for the secondary outcomes IMVC (N)

\begin{tabular}{lllll}
\hline & $\begin{array}{l}\text { Pillai's trace } \\
\left(r^{2}=S_{\text {Bet }} / S S_{\text {Tot }}\right)\end{array}$ & $L\left[(N-1) r^{2}\right]$ & $p$ & $E S\left(\eta^{2}\right)$ \\
\hline $\begin{array}{l}\text { IMVC right ex (N) (time } \\
\text { effects) }\end{array}$ & 0.001 & 0.006 & 0.994 & 0.001 \\
$\begin{array}{l}\text { IMVC right ex (N) } \\
\text { (interaction effects) }\end{array}$ & 0.28 & 5.41 & $0.01^{*}$ & 0.28 \\
$\begin{array}{l}\text { IMVC left ex (N) } \\
\text { (time effects) }\end{array}$ & 0.01 & 0.007 & 0.993 & 0.001 \\
$\begin{array}{l}\text { IMVC left ex (N) } \\
\text { (interaction effects) }\end{array}$ & 0.34 & 7.16 & $0.003^{*}$ & 0.51 \\
$\begin{array}{l}\text { IMVC right flex (N) } \\
\text { (time effects) }\end{array}$ & 0.27 & 1.62 & 0.232 & 0.27 \\
$\begin{array}{l}\text { IMVC right flex (N) } \\
\text { (interaction effects) }\end{array}$ & 0.001 & 0.003 & 0.997 & 0.001 \\
$\begin{array}{l}\text { IMVC left flex (N) } \\
\text { (time effects) }\end{array}$ & 0.15 & 2.54 & 0.097 & 0.15 \\
$\begin{array}{l}\text { IMVC left flex (N) } \\
\text { (interaction effects) }\end{array}$ & 0.001 & 0.001 & 0.999 & 0.001 \\
& 0.09 & 1.33 & 0.282 & 0.09 \\
\hline
\end{tabular}

IMVC: isometric maximum voluntary contraction; ${ }^{\circ}$ : significant difference $p<0.05$, *: siginificant difference after Bonferroni adjustment $p<0.0125$; ES: effect size ( $\eta 2=.01$; small effect, $\eta 2=.06$; moderate effect, $\eta 2=.14$; large effect) 
Table 4 ANOVA with repeated measurements (ranks) intergroup-by-time effects and group-by-time interaction for the secondary outcomes IRFD ( $\mathrm{N} / \mathrm{ms}$ )

\begin{tabular}{lcccc}
\hline & $\begin{array}{l}\text { Pillai's trace } \\
\left(\mathrm{r}^{2}=\mathrm{SS}_{\text {Bet }} / \mathrm{SS}_{\text {Tot }}\right)\end{array}$ & $\mathrm{L}\left[(\mathrm{N}-1) \mathrm{r}^{2}\right]$ & $p$ & $\mathrm{ES}\left(\mathrm{n}^{2}\right)$ \\
\hline $\begin{array}{l}\text { IRFD right ex (N/ms) } \\
\text { (time effects) }\end{array}$ & 0.001 & 0.005 & 0.995 & 0.001 \\
$\begin{array}{l}\text { IRFD right ex (N/ms) } \\
\text { (interaction effects) }\end{array}$ & 0.238 & 4.37 & $0.022^{*}$ & 0.24 \\
$\begin{array}{l}\text { IRFD left ex (N/ms) } \\
\text { (time effects) }\end{array}$ & 0.43 & 10.73 & $0.001^{*}$ & 0.43 \\
$\begin{array}{l}\text { IRFD left ex (N/ms) } \\
\text { (interaction effects) }\end{array}$ & 0.02 & 0.03 & 0.97 & 0.002 \\
$\begin{array}{l}\text { IRFD right flex (N/ms) } \\
\text { (time effects) }\end{array}$ & 0.68 & 29.38 & $0.001^{*}$ & 0.68 \\
$\begin{array}{l}\text { IRFD right flex (N/ms) } \\
\text { (interaction effects) }\end{array}$ & 1.45 & 6.30 & $0.007^{*}$ & 0.59 \\
$\begin{array}{l}\text { IRFD left flex (N/ms) } \\
\text { (time effects) }\end{array}$ & 0.85 & 52.61 & $0.001^{*}$ & 0.85 \\
$\begin{array}{l}\text { IRFD left flex (N/ms) } \\
\text { (interaction effects) }\end{array}$ & 0.52 & 9.65 & $0.001^{*}$ & 0.52 \\
\hline
\end{tabular}

IRFD: isometric rate of force development; ${ }^{\circ}$ : significant difference $p<0.05,{ }^{*}$ : siginificant difference after Bonferroni adjustment $p<0.0125$; ES: effect size ( $\eta 2=.01$; small effect, $\eta 2=.06$; moderate effect, $\eta 2=.14$; large effect)

movements were shown for IRFDsub at 0-30 ms, 0-50 ms, 0-100 ms and 100-200 ms (Additional files 9, 10, 11, 12, $13,14,15$ and 16).

\section{Discussion}

This study aimed to assess the effects of SR-WBV \& Video Dance Game Training that was accompanied with motivational instructions in LTC elderly on lower extremity physical function and leg muscle properties. We hypothesised that an intervention program that targets motor control will effect on physical functioning and muscle strength levels of LTC elderly. The results of the study demonstrate that a combination of SR-WBV and DVG may be used as a skilling-up exercise for LTC elderly because of significant SPPB score change values in IG (+58.8 \%) compared to SG (-4.0\%) and concomitant significant strength improvements seen in Fsub, IRFD, and IRFDsub in IG compared to SG.

Coaching the LTC participants in both groups with a professional exercise instructor to enhance exercise participation, aimed to ensure that the targeted exercise frequencies and levels would be reached, and to prevent attrition. This approach showed to be rather succesfull. We demonstrated the feasibility of a motivational approach through high adherence rates for LTC dwelling older people randomised in this clinical trial. Our target of $75 \%$ compliance for the 8-weeks training project was by far attained. Furthermore, no individuals were considered non-compliant for the training. Thus, compliance with the exercise interventions and retesting was excellent. Compared with median rates for recruitment, attrition and adherence in falls prevention interventions in institutional settings for clinical trials [82] we achieved better rates. However, we report on values after 8 training weeks. Nyman and Victor [82] and Fuchs and colleagues [64] report values that may be expected by 12 months. In future trials with LTC individuals the follow-up period for the assessment of adherence and attrition should, therefore, preferably be extended to a similar time frame to facilitate comparability with reference values.

Previous studies in elderly individuals have referred to the usefulness of WBV training on both muscle strength [83-87] and balance [88-91]. Playing certain types of Video Games had an effect on muscle strength [92], balance [93], and gait [94]. However, few studies found results with similar high effect sizes as this study. The combination of SR-WBV and DVG might, therefore, be more effective in activating the sensorimotor system compared to published studies that investigated solely training using one of these approaches [51, 83, 92-95]. However, future studies that compare both approaches against each other are needed to substantiate or refute this assumption. It is known that traditional strengthening improves muscle strength as a result of an improved neural drive and muscle hypertrophy [96-98]. Gruber and Gollhofer [72] postulated that sensorimotor training had a large influence on the neuromuscular system at the initiation of production of rate of force development and neuromuscular activation at the onset of voluntary actions. The motoneuron outputs induced by sensorimotor training comprise elevated central motor drive, motoneuron recruitment or firing frequency, alterations in synchronisation of motor unit firing, and reduced presynaptic inhibition [72, 99]. However, the increase in IRFD after sensorimotor training is not associated with an increase in maximum voluntary contraction [72]. As a sensorimotor training method, SR-WBV and DVG seems, therefore, to mainly affect the neural drive.

The results of the present study potentially have important functional consequences. Age-related degenerative processes, referred to as dynapenia, are considered a contributing factor to loss of independence in daily living [20]. High RFD is important in various activities of daily life where a sudden strength capacity is required, and to counteract sudden perturbations, e.g., in postural control to avoid falls $[98,100]$. A typical contraction time involved in such movements is between 50 to $250 \mathrm{~ms}$. In contrast, the time to reach maximum strength in most human muscles is over $300 \mathrm{~ms}$, e.g., for knee extensors [101]. On the basis of the previously described reasoning it seems plausible that IMVC did not significantly change during sensorimotor training. However, physical performance improved significantly. RFD is more closely related to physical performance than IMVC $[102,103]$. The result of this study is in accordance with Bottaro et al. [104], who 
Table 5 Between group effects at BASE, $4 \mathrm{~W}$ and $8 \mathrm{~W}$ on SPPB, IMVC and IRFD

\begin{tabular}{|c|c|c|c|c|c|c|}
\hline & BASE & $\mathrm{p} / \mathrm{n}^{2}$ & $4 W$ & $\mathrm{p} / \eta^{2}$ & $8 W$ & $\mathrm{p} / \eta^{2}$ \\
\hline SPPB (Score) (IG) & $2.9 \pm 1.7$ & $0.16 / 0.07$ & $5.6 \pm 2.9$ & $0.01 * / 0.21$ & $7.13 \pm 3.2$ & $0.004 * / 0.26$ \\
\hline SPPB (Score) (SG) & $3.9 \pm 1.5$ & & $3.4 \pm 1.2$ & & $3.7 \pm 1.2$ & \\
\hline IMVC right ex (N) (IG) & $136.0 \pm 58.4$ & $0.62 / 0.01$ & $138.4 \pm 56.0$ & $0.81 / 0.002$ & $180.1 \pm 71.2$ & $0.10 / 0.09$ \\
\hline IMVC right ex (N) (SG) & $157.9 \pm 75.7$ & & $134.4 \pm 59.0$ & & $147.8 \pm 62.8$ & \\
\hline IMVC left ex (N) (IG) & $140.4 \pm 89.3$ & $0.97 / 0.001$ & $163.1 \pm 78.1$ & $0.12 / 0.08$ & $194.6 \pm 90.2$ & $0.04^{\circ} / 0.26$ \\
\hline IMVC left ex (N) (SG) & $132.5 \pm 56.0$ & & $119.5 \pm 54.0$ & & $126.1 \pm 65.7$ & \\
\hline IMVC right flex (N) (IG) & $61.0 \pm 29.0$ & 0.88/0.001 & $74.4 \pm 30.7$ & $0.29 / 0.04$ & $87.0 \pm 38.5$ & $0.08 / 0.11$ \\
\hline IMVC right flex (N) (SG) & $64.1 \pm 31.0$ & & $67.0 \pm 31.7$ & & $67.0 \pm 31.2$ & \\
\hline IMVC left flex (N) (IG) & $73.5 \pm 42.6$ & $0.37 / 0.03$ & $79.0 \pm 44.8$ & $0.15 / 0.07$ & $86.9 \pm 36.8$ & $0.03^{\circ} / 0.15$ \\
\hline IMVC left flex (N) (SG) & $60.3 \pm 24.5$ & & $60.4 \pm 25.3$ & & $64.4 \pm 16.5$ & \\
\hline IRFD right ex (N/ms) (IG) & $0.46 \pm 0.3$ & $0.70 / 0.005$ & $0.56 \pm 0.3$ & $0.02 * / 0.06$ & $0.72 \pm 0.4$ & $0.004 * / 0.25$ \\
\hline IRFD right ex (N/ms) (SG) & $0.41 \pm 0.3$ & & $0.40 \pm 0.2$ & & $0.39 \pm 0.1$ & \\
\hline IRFD left ex (N/ms) (IG) & $0.48 \pm 0.4$ & $0.97 / 0.001$ & $0.69 \pm 0.5$ & $0.02 * / 0.19$ & $0.82 \pm 0.5$ & $0.001 * / 0.41$ \\
\hline IRFD left ex (N/ms) (SG) & $0.38 \pm 0.3$ & & $0.34 \pm 0.1$ & & $0.29 \pm 0.1$ & \\
\hline IRFD right flex (N/ms) (IG) & $0.13 \pm 0.1$ & $0.14 / 0.08$ & $0.25 \pm 0.1$ & $0.01 * / 0.23$ & $0.39 \pm 1.5$ & $<0.001 * / 0.64$ \\
\hline IRFD right flex (N/ms) (SG) & $0.19 \pm 0.1$ & & $0.15 \pm 0.1$ & & $0.15 \pm 0.1$ & \\
\hline IRFD left flex (N/ms) (IG) & $0.17 \pm 0.1$ & $0.97 / 0.001$ & $0.26 \pm 0.2$ & $0.02 * / 0.19$ & $0.39 \pm 0.2$ & $<0.001 * / 0.42$ \\
\hline IRFD left flex (N/ms) (SG) & $0.15 \pm 0.1$ & & $0.14 \pm 0.1$ & & $0.15 \pm 0.1$ & \\
\hline
\end{tabular}

IG: intervention group, SG: sham group, SPPB: Short Physical Performance Battery, IMVC: isometric maximal voluntary contraction, ex: extension, flex: flexion, N: Newton, IRFD: isometric rate of force development, $\mathrm{N} / \mathrm{ms}$ : NewtoN/mseconds, ${ }^{\circ}$ : significant difference between groups $p<0.05, *$ : siginificant difference between groups after Bonferroni correction $p<0.025, \eta^{2}$ : effect size: $\eta^{2}=.01$; small effect, $\eta^{2}=.06$; moderate effect, $\eta^{2}=.14$; large effect

were able to find an increase in RFD in parallel with an improvement in physical performance.

This study presents a mean change after four weeks of about 2.7 points and after eight weeks of 4.2 points on the SPPB scale in the IG. After four weeks the SG shows a mean change of about -0.5 and after eight weeks a mean change -0.2 points on the SPPB scale. Changes of about 1 point on the SPPB scale are substantial [105]. From a clinical standpoint, low SPPB point scores have a predictive value in activities in daily living [69], loss of mobility [106], admission to nursing facilities, disability [66, 69], hospitalization [107] and mortality [108]. In addition, physical performance measures have been used to test the efficacy of preventive strategies [109]. An improvement on the SPPB point scale through SR-WBV and DVG may reduce the risk of major mobility disability. Maintaining mobility is a central component in sustaining independence in daily living. Drey et al. [105] described that muscle strength and muscle power during follow up interventions have been shown to be equally beneficial for increasing physical function in elderly individuals. Future studies should be designed with adequate follow up measures to further investigate and record the possible impact of SR-WBV and DVG on the activities of daily living.
An additional advantage of this current study over previous WBV or DVG investigations in the elderly is the use of the classification system defined by Zeyfang and Braun [110]. Elderly individuals are not a homogeneous group. There are biologically elderly individuals who still feel young at heart, having a high physical fitness and performance level, and anticipating a few decades of life expectancy ahead of them. On the other spectrum frail elderly can be situated. Therefore, functional status of participating older individuals should be emphasized in training studies. To manage elderly individuals' needs in consideration of diagnostic or treatment goals or maintenance of health, the framework "Go-Go, Slow-Go and No-Go" could be used. This classification was introduced by Zeyfang and Braun [110] classifying older adults as "being an independent person" (Go-Go); "being a needy person with a slight handicap" (Slow-Go); and "being a person in need of care with severe functional limitation" (No-Go). The need for care may be defined as depending permanently on assistance (No-Go) or depending on support in everyday activities such as dressing, body care, eating, using the toilet, mobility, and planning the day (Slow-Go) [111]. A systematic review indicated that older adults categorized in these groups react differently when provided with the same training stimuli [38]. Our study reflects the need to 
consider the functional status of the included participants. Bautmans et al. [88] included all residents in a nursing home within dependence categories " $\mathrm{O}$ " (do not need assistance), "A" (need assistance in two ADLs: washing and dressing) and "B" (require assistance in three ADLs) according to the scale of Katz et al. [112]. When their participants are categorised with our classification it becomes apparent that only Go-Go and Slow-Go elderly were included. This finding is reflective of the observation that there are only few studies $[51,83,95,113]$ that have focused separately on the Go-Go, Slow-Go and No-Go classification of older individuals.

There are some limitations in this study that should be mentioned. It was a single blind study. Studies where the examiner is not blinded might be at a higher risk of attrition [114] or assessment bias [115]. Future studies should, therefore, try to replicate our findings using a design where the examiner is blinded. No long-lasting effects follow-up measurements were obtained on the impact of the program on functional performance, strength or fall rates. Future studies should carry out such follow-up measurements to evaluate lasting effects. Furthermore, we used performance (SPPB) and impairment level (lower body muscle strength) based measures as proxies for PA [116, 117]. Although these measures are correlated and randomised clinical trial intervention studies in older adults show that PA improves measures of physical performance $[109,118]$ future studies should include quantified measures of PA instead of proxy measures.

\section{Conclusions}

During SR-WBV and DVG intervention, three times a week within eight weeks physical performance and rate of force development improved significantly compared to sham intervention in No-Go (need-of-care) elderly residing in LTC. The results of this study indicate that SR-WBV and DVG can be used as a skilling up training regime for No-Go elderly individuals. Future investigations are warranted and should include follow-up measures, together with additional measures of functional strength, balance, gait and fall risk.

\section{Endnotes}

${ }^{1}$ The ADL Hierarchy Scale of the RAI groups activities of daily living according to the stage of the disablement process in which they occur. Early loss ADLs (for example, dressing) are assigned lower scores than late loss ADLs (for example, eating). The ADL Hierarchy ranges from 0 (no impairment) to 6 (total dependence); source: Morris JN, Fries BE, Morris SA. (1999) Scaling ADLs within the MDS. Journals of Gerontology: Medical Sciences 54(11):M546-M553)

\section{Additional files}

\begin{abstract}
Additional file 1: ANOVA with repeated measurements (ranks) intergroup-by-time effects and group-by-time interaction for the secondary outcomes Fsub 30 ms (N). (DOCX 18 kb)
\end{abstract}

Additional file 2: Outcome Fsub 30ms ( $N$ ) data and between group comparison at BASE, $4 \mathrm{~W}$ and $8 \mathrm{~W}$. (DOCX $19 \mathrm{~kb}$ )

Additional file 3: ANOVA with repeated measurements (ranks) intergroup-by-time effects and group-by-time interaction for the secondary outcomes Fsub 50 ms (N). (DOCX 19 kb)

Additional file 4: Outcome values af Fsub $50 \mathrm{~ms}(\mathrm{~N})$ data and between group comparison at BASE, 4 W and 8 W. (DOCX 19 kb)

Additional file 5: ANOVA with repeated measurements (ranks) intergroup-by-time effects and group-by-time interaction for the secondary outcomes Fsub 100 ms (N). (DOCX 18 kb)

Additional file 6: Outcome values af Fsub 100ms (N) data and between group comparison at BASE, $4 \mathrm{~W}$ and $8 \mathrm{~W}$. (DOCX $20 \mathrm{~kb}$ )

Additional file 7: ANOVA with repeated measurements (ranks) intergroup-by-time effects and group-by-time interaction for the secondary outcomes Fsub 2000 ms (N). (DOCX 18 kb)

Additional file 8: Outcome values af Fsub 200ms (N) data and between group comparison at BASE, $4 \mathrm{~W}$ and $8 \mathrm{~W}$. (DOCX $19 \mathrm{~kb}$ )

Additional file 9: ANOVA with repeated measurements (ranks) intergroup-by-time effects and group-by-time interaction for the secondary outcomes IRFDsub 0-30 ms (N/ms). (DOCX $18 \mathrm{~kb}$ )

Additional file 10: Outcome values af IRFDsub 0-30 ms (N/ms) data and between group comparison at BASE, 4 W and 8 W. (DOC 36 kb)

Additional file 11: ANOVA with repeated measurements (ranks) intergroup-by-time effects and group-by-time interaction for the secondary outcomes IRFDsub 0-50 ms (N/ms). (DOC 30 kb)

Additional file 12: Outcome values af IRFDsub 0-50 ms (N/ms) data and between group comparison at BASE, $4 \mathrm{~W}$ and $8 \mathrm{~W}$. (DOC $36 \mathrm{~kb}$ )

Additional file 13: ANOVA with repeated measurements (ranks) intergroup-by-time effects and group-by-time interaction for the secondary outcomes IRFDsub 0-100 ms (N/ms). (DOC $30 \mathrm{~kb}$ )

Additional file 14: Outcome values af RFDsub 0-100 ms ( $\mathrm{N} / \mathrm{ms})$ data and between group comparison at BASE, 4 W and 8 W. (DOC $36 \mathrm{~kb}$ )

Additional file 15: ANOVA with repeated measurements (ranks) intergroup-by-time effects and group-by-time interaction for the secondary outcomes IRFDsub 100-200 ms (N/ms). (DOC 30 kb)

Additional file 16: Outcome values af RFDsub 100-200 ms (N/ms) data and between group comparison at BASE, 4 W and 8 W. (DOC $35 \mathrm{~kb}$ )

\section{Abbrevations}

ADLs, activity of daily living; ANOVA, analyses of varianc; DVG, dance video game; ES, effect size; Fsub, Submaximal force; Hz, hertz; IG, intervention group; IMVC, isometric voluntary contraction; IRFD, isometric rate of force development; IRFDsub, submaximal IRFD values, Long-term care; LTC, MMSE, Mini-Mental Status Examination; ms, millisseconds; N, Newton; N/ms, Newton/ milliseconds; RAl, Resident Assessment Instrument; RFD, rate of force development; SH, sham group; SPPB, Short Physival Performance Battery; SR-WBV, stochastic resonance whole-body vibration; WBV, whole-body vibration.

\section{Acknowledgements}

We would like to thank Bennie Ross for proof reading and Patric Eichelberger for strength measurement data processing on Matlab.

\section{Authors' contributions}

SR and EdB conceived the idea of this study. SR, LR, HB, RB and EdB participated in the conception and design of the study. SR supervised the WBV trainings session and Data collection. SR and EdB conducted the statistical analyses. $S R, R B$ and $E d B$ wrote the first manuscript version. $S R, L R$, $\mathrm{RH}, \mathrm{DS}, \mathrm{RdB}$, and $\mathrm{EdB}$ were involved in drafting or revising the manuscript. All authors read and approved the final manuscript. 


\section{Competing interests}

The authors declare no potential conflict of interest with respect to the authorship or publication of this article.

\begin{abstract}
Author details
'Discipline Physiotherapy, Health, Bern University of Applied Sciences, Bern, Switzerland. ${ }^{2}$ Department of Sport Science, Wolfgang-Goethe University Frankfurt, Frankfurt, Germany. ${ }^{3}$ Department of Epidemiology, Maastricht University, CAPHRI School for Public Health and Primary Care, Maastricht, The Netherlands. ${ }^{4}$ Centre for Evidence Based Physiotherapy, Maastricht University, PO Box 6166200, MD, Maastricht, The Netherlands. ${ }^{5}$ Department of Health Sciences and Technology, Institute of Human Movement Sciences and Sport, ETH Zurich, Switzerland Wolfgang-Pauli-Str. 27, HIT J 31.2, CH-8093 Zurich, Switzerland.
\end{abstract}

Received: 31 October 2015 Accepted: 21 May 2016

Published online: 28 May 2016

\section{References}

1. Rikli RE, Jones CJ. Development and validation of a functional fitness test for community-residing older adults. J Aging Phys Activ. 1999;7(2):129-61.

2. Fried LP, Ferrucci L, Darer J, Williamson JD, Anderson G. Untangling the concepts of disability, frailty, and comorbidity: Implications for improved targeting and care. J Gerontol a-Biol. 2004;59(3):255-63.

3. Markle-Reid M, Browne G. Conceptualizations of frailty in relation to older adults. J Adv Nurs. 2003:44(1):58-68.

4. Leveille SG, Wagner EH, Davis C, Grothaus L, Wallace J, LoGerfo M, Kent D. Preventing disability and managing chronic illness in frail older adults: a randomized trial of a community-based partnership with primar care. J Am Geriatr Soc 1998;46(10):1191-8.

5. Baert V, Gorus E, Mets T, Geerts C, Bautmans I. Motivators and barriers for physical activity in the oldest old: a systematic review. Ageing Res Rev. 2011:10(4):464-74.

6. Freiberger E, Sieber C, Pfeifer K. Physical activity, exercise, and sarcopenia future challenges. Wien Med Wochenschr. 2011;161(17-18):416-25.

7. Benjamin K, Edwards N, Ploeg J, Legault F. Barriers to physical activity and restorative care for residents in long-term care: a review of the literature. J Aging Phys Act. 2014;22(1):154-65.

8. De Souto BP, Demougeot $L$, Vellas B, Rolland Y. How much exercise are older adults living in nursing homes doing in daily life? A cross-sectional study. J Sports Sci. 2015;33(2):116-24.

9. Roubenoff R, Hughes VA. Sarcopenia: current concepts. J Gerontol Ser A Biol Med Sci. 2000;55(12):M716-724.

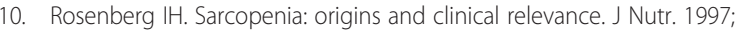
127(5 Suppl):990S-1S.

11. Clark BC, Fernhall B, Ploutz-Snyder LL. Adaptations in human neuromuscular function following prolonged unweighting: I. Skeletal muscle contractile properties and applied ischemia efficacy. J Appl Physiol. 2006;101(1):256-63.

12. Delmonico MJ, Harris TB, Visser M, Park SW, Conroy MB, Velasquez-Mieyer P, Boudreau R, Manini TM, Nevitt M, Newman AB et al. Longitudinal study of muscle strength, quality, and adipose tissue infiltration. Am J Clin Nutr. 2009;90(6):1579-85.

13. Kawakami Y, Akima H, Kubo K, Muraoka Y, Hasegawa H, Kouzaki M, Imai M, Suzuki Y, Gunji A, Kanehisa H et al. Changes in muscle size, architecture, and neural activation after 20 days of bed rest with and without resistance exercise. Eur J Appl Physiol. 2001;84(1-2):7-12.

14. Clark BC, Manini TM, Bolanowski SJ, Ploutz-Snyder LL. Adaptations in human neuromuscular function following prolonged unweighting: II. Neurological properties and motor imagery efficacy. J Appl Physiol. 2006;101(1):264-72.

15. Clark BC, Pierce JR, Manini TM, Ploutz-Snyder LL. Effect of prolonged unweighting of human skeletal muscle on neuromotor force control. Eur J Appl Physiol. 2007;100(1):53-62.

16. Clark BC. In vivo alterations in skeletal muscle form and function after disuse atrophy. Med Sci Sports Exerc. 2009;41(10):1869-75.

17. Clark BC, Issac LC, Lane JL, Damron LA, Hoffman RL. Neuromuscular plasticity during and following 3 weeks of human forearm cast immobilization. J Appl Physiol. 2008;105(3):868-78.

18. Clark BC, Taylor JL, Hoffman RL, Dearth DJ, Thomas JS. Cast immobilization increases long-interval intracortical inhibition. Muscle Nerve. 2010;42(3):363-72.

19. Hill AV. The mechanics of active muscle. Proc Roy Soc Lond (Biol). 1953;141:104-17.
20. Clark BC, Manini TM. What is dynapenia? Nutrition. 2012;28(5):495-503.

21. Manini TM, Clark BC. Dynapenia and aging: an update. J Gerontol Ser A Biol Med Sci. 2012;67(1):28-40.

22. Duchateau J, Enoka RM. Neural adaptations with chronic activity patterns in able-bodied humans. Am J Phys Med Rehabil. 2002;81(11 Suppl):S17-27.

23. Clark BC, Taylor JL. Age-related changes in motor cortical properties and voluntary activation of skeletal muscle. Curr Aging Sci. 2011;4(3):192-9.

24. Ward RE, Boudreau RM, Caserotti P, Harris TB, Zivkovic S, Goodpaster BH, Satterfield S, Kritchevsky SB, Schwartz AV, Vinik Al et al. Sensory and motor peripheral nerve function and incident mobility disability. J Am Geriatr Soc. 2014;62(12):2273-9.

25. Ward RE, Boudreau RM, Caserotti P, Harris TB, Zivkovic S, Goodpaster BH, Satterfield S, Kritchevsky S, Schwartz AV, Vinik Al et al. Sensory and Motor Peripheral Nerve Function and Longitudinal Changes in Quadriceps Strength. J Gerontol a-Biol. 2015;70(4):464-70.

26. Borghuis J, Hof AL, Lemmink KA. The importance of sensory-motor control in providing core stability: implications for measurement and training. Sports Med. 2008;38(11):893-916

27. Comerford MJ, Mottram SL. Movement and stability dysfunctioncontemporary developments. Man Ther. 2001;6(1):15-26.

28. Scott SH. Optimal feedback control and the neural basis of volitional motor control. Nat Rev Neurosci. 2004;5(7):532-46.

29. Radebold A, Cholewicki J, Polzhofer GK, Greene HS. Impaired postural control of the lumbar spine is associated with delayed muscle response times in patients with chronic idiopathic low back pain. Spine. 2001;26(7):724-30.

30. McDonnell MD, Ward LM. The benefits of noise in neural systems: bridging theory and experiment. Nat Rev Neurosci. 2011;12(7):415-26.

31. Moss F, Ward LM, Sannita WG. Stochastic resonance and sensory information processing: a tutorial and review of application. Clin Neurophysiol. 2004;115(2):267-81.

32. Collins JJ, Imhoff TT, Grigg P. Noise-enhanced tactile sensation. Nature. 1996:383(6603):770.

33. Cordo P, Inglis JT, Verschueren S, Collins JJ, Merfeld DM, Rosenblum S, Buckley S. Moss F. Noise in human muscle spindles. Nature. 1996:383(6603):769-70.

34. Priplata A, Niemi J, Salen M, Harry J, Lipsitz LA, Collins JJ. Noise-enhanced human balance control. Phys Rev Lett. 2002;89(23):238101.

35. Collins JJ, Priplata AA, Gravelle DC, Niemi J, Harry J, Lipsitz LA. Noiseenhanced human sensorimotor function. IEEE Eng Med Biol Mag. 2003; 22(2):76-83

36. Chanou K, Gerodimos V, Karatrantou K, Jamurtas A. Whole-body vibration and rehabilitation of chronic diseases: a review of the literature. J Sports Sci Med. 2012;11(2):187-200.

37. Rogan S, Hilfiker R, Schenk A, Vogler A, Taeymans J. Effects of whole-body vibration with stochastic resonance on balance in persons with balance disability and falls history - a systematic review. Res Sports Med. 2014:22(3):294-313.

38. Rogan S, de Bruin ED, Radlinger L, Joehr C, Wyss C, Stuck NJ, Bruelhart Y, de Bie RA, Hilfiker R. Effects of whole-body vibration on proxies of muscle strength in old adults: a systematic review and meta-analysis on the role of physical capacity level. Eur Rev Aging Phys Act. 2015;12:12.

39. Mendez-Balbuena I, Manjarrez E, Schulte-Monting J, Huethe F, Tapia JA, Hepp-Reymond MC, Kristeva R. Improved sensorimotor performance via stochastic resonance. J Neurosci. 2012;32(36):12612-8.

40. Rogan S, Hilfiker R, Schmid S, Radlinger L. Stochastic resonance whole-body vibration training for chair rising performance on untrained elderly: a pilot study. Arch Gerontol Geriatr. 2012:55(2):468-73.

41. Haas CT, Turbanski S, Kessler K, Schmidtbleicher D. The effects of random whole-body-vibration on motor symptoms in Parkinson's disease. NeuroRehabilitation. 2006;21(1):29-36.

42. Moss F, Milton JG. Medical technology: balancing the unbalanced. Nature. 2003:425(6961):911-2.

43. Elfering A, Arnold S, Schade V, Burger C, Radlinger L. Stochastic resonance whole-body vibration, musculoskeletal symptoms, and body balance: a worksite training study. Saf Health Work. 2013;4(3):149-55.

44. de Bruin ED, Schoene D, Pichierri G, Smith ST. Use of virtual reality technique for the training of motor control in the elderly. Some theoretical considerations. Z Gerontol Geriatr. 2010:43(4):229-34.

45. Pichierri G, Wolf $P$, Murer $K$, de Bruin ED. Cognitive and cognitive-motor interventions affecting physical functioning: a systematic review. BMC Geriatr. 2011;11:29

46. Rogan S, Radlinger L, Schmidtbleicher D, de Bie RA, de Bruin ED. Preliminary inconclusive results of a randomised double blinded cross-over pilot trial in 
long-term-care dwelling elderly assessing the feasibility of stochastic resonance whole-body vibration. Eur Rev Aging Phys Act. 2015;12(5).

47. Ferrucci L, Guralnik JM, Studenski S, Fried LP, Cutler Jr GB, Walston JD. Designing randomized, controlled trials aimed at preventing or delaying functional decline and disability in frail, older persons: a consensus report. J Am Geriatr Soc. 2004;52(4):625-34

48. Fairhall N, Langron C, Sherrington C, Lord SR, Kurrle SE, Lockwood K, Monaghan N, Aggar C, Gill L, Cameron ID. Treating frailty-a practical guide. BMC Med. 2011;9:83.

49. Campbell MK, Piaggio G, Elbourne DR, Altman DG, Group C. Consort 2010 statement: extension to cluster randomised trials. BMJ. 2012;345:e5661.

50. Cruz-Jentoft AJ, Baeyens JP, Bauer JM, Boirie Y, Cederholm T, Landi F, Martin FC, Michel JP, Rolland Y, Schneider SM et al. Sarcopenia: European consensus on definition and diagnosis: Report of the European Working Group on Sarcopenia in Older People. Age Ageing. 2010;39(4):412-23.

51. Kessler J, Radlinger L, Baur H, Rogan S. Effect of stochastic resonance whole body vibration on functional performance in the frail elderly: A pilot study. Arch Gerontol Geriatr. 2014;59(2):305-11.

52. Ahlborg L, Andersson C, Julin P. Whole-body vibration training compared with resistance training: effect on spasticity, muscle strength and motor performance in adults with cerebral palsy. J Rehabil Med. 2006;38(5):302-8

53. Rogan S, Radlinger $L$, Hilfiker R, Schmidtbleicher D, de Bie RA, de Bruin ED. Feasibility and effects of applying stochastic resonance whole-body vibration on untrained elderly: a randomized crossover pilot study. BMC Geriatr. 2015;15(25).

54. Kaut O, Allert N, Coch C, Paus S, Grzeska A, Minnerop M, Wullner U. Stochastic resonance therapy in Parkinson's disease. NeuroRehabilitation. 2011;28(4):353-8.

55. Kaut O, Jacobi H, Coch C, Prochnicki A, Minnerop M, Klockgether T, Wullner $U$. A randomized pilot study of stochastic vibration therapy in spinocerebellar ataxia. Cerebellum. 2014;13(2):237-42.

56. Elfering A, Thomann J, Schade V, Radlinger L. Stochastic resonance whole body vibration reduces musculoskeletal pain: A randomized controlled trial. World J Orthop. 2011;2(12):116-20.

57. Pichierri G, Murer K, de Bruin ED. A cognitive-motor intervention using a dance video game to enhance foot placement accuracy and gait under dual task conditions in older adults: a randomized controlled trial. BMC Geriatr. 2012;12:74

58. Pichierri G, Coppe A, Lorenzetti S, Murer K, de Bruin ED. The effect of a cognitive-motor intervention on voluntary step execution under single and dual task conditions in older adults: a randomized controlled pilot study. Clin Interv Aging. 2012;7:175-84.

59. O'Keeffe K. Dancing Monkeys (Automated creation of step files for Dance Dance Revolution). PhD. London: Imperial College; 2003.

60. Fraser SA, Elliott V, de Bruin ED, Bherer L, Dumoulin C. The Effects of Combining Videogame Dancing and Pelvic Floor Training to Improve DualTask Gait and Cognition in Women with Mixed-Urinary Incontinence. Games Health J. 2014;3(3):172-8.

61. Eggenberger $P$, Schumacher $V$, Angst $M$, Theill $N$, de Bruin ED. Does multicomponent physical exercise with simultaneous cognitive training boost cognitive performance in older adults? A 6-month randomized controlled trial with a 1-year follow-up. Clin Interv Aging. 2015;10:1335-49.

62. Zech A, Drey M, Freiberger E, Hentschke C, Bauer JM, Sieber CC, Pfeifer K. Residual effects of muscle strength and muscle power training and detraining on physical function in community-dwelling prefrail older adults: a randomized controlled trial. BMC Geriatr. 2012;12:68.

63. Resnick B. Functional performance of older adults in a long-term care setting. Clin Nurs Res. 1998;7(3):230-46. discussion 246-239.

64. Fuchs R, Goehner W, Seelig H. Long-term effects of a psychological group intervention on physical exercise and health: the MoVo concept. J Phys Act Health. 2011;8(6):794-803.

65. Fuchs R, Göhner W, Seelig H, Fleitz A, Mahler C, Schittich I. Lebensstilintegrierte sportliche Aktivität: Ergebnisse der MoVo-LISA Interventionsstudie. Bewegungstherapie und Gesundheitssport. 2010;26:270-6.

66. Guralnik JM, Simonsick EM, Ferrucci L, Glynn RJ, Berkman LF, Blazer DG, Scherr PA, Wallace RB. A short physical performance battery assessing lower extremity function: association with self-reported disability and prediction of mortality and nursing home admission. J Gerontol. 1994; 49(2):M85-94

67. Evans WJ. Functional outcomes for clinical trials in frail older persons: Time to be moving. J Gerontol a-Biol. 2008;63(2):160-4.
68. Ostir GV, Volpato S, Fried LP, Chaves P, Guralnik JM. Reliability and sensitivity to change assessed for a summary measure of lower body function: results from the Women's Health and Aging Study. J Clin Epidemiol. 2002;55(9):916-21.

69. Guralnik JM, Ferrucci L, Pieper CF, Leveille SG, Markides KS, Ostir GV Studenski S, Berkman LF, Wallace RB. Lower extremity function and subsequent disability: consistency across studies, predictive models, and value of gait speed alone compared with the short physical performance battery. J Gerontol Ser A Biol Med Sci. 2000;55(4):M221-231.

70. Guralnik JM, Ferrucci L, Simonsick EM, Salive ME, Wallace RB. Lowerextremity function in persons over the age of 70 years as a predictor of subsequent disability. N Engl J Med. 1995;332(9):556-61.

71. Ferrucci L, Penninx BW, Leveille SG, Corti MC, Pahor M, Wallace R, Harris TB, Havlik RJ, Guralnik JM. Characteristics of nondisabled older persons who perform poorly in objective tests of lower extremity function. J Am Geriatr Soc. 2000;48(9):1102-10.

72. Gruber M, Gollhofer A. Impact of sensorimotor training on the rate of force development and neural activation. Eur J Appl Physiol. 2004;92(1-2):98-105.

73. Mebes C, Amstutz A, Luder G, Ziswiler HR, Stettler M, Villiger PM, Radlinger $\mathrm{L}$. Isometric rate of force development, maximum voluntary contraction, and balance in women with and without joint hypermobility. Arthritis Rheum. 2008:59(11):1665-9.

74. Kwon S, Perera S, Pahor M, Katula JA, King AC, Groessl EJ, Studenski SA. What is a meaningful change in physical performance? Findings from a clinical trial in older adults (the LIFE-P study). J Nutr Health Aging. 2009; 13(6):538-44.

75. Perera S, Mody SH, Woodman RC, Studenski SA. Meaningful change and responsiveness in common physical performance measures in older adults. J Am Geriatr Soc. 2006;54(5):743-9.

76. Perera S, Studenski S, Newman A, Simonsick E, Harris T, Schwarts A, Visser $M$. Are estimates of meaningful decline in mobility performance consistent among clinically important subgroups? (Health ABC Study). J Gerontol A Biol Sci Med Sci. 2014;69(10):1260-8.

77. Hollis S, Campbell F. What is meant by intention to treat analysis? Survey of published randomised controlled trials. BMJ. 1999;319(7211):670-4.

78. Puri ML, Sen PK. A class of rank order tests for a general linear hypothesis. Ann Math Stat. 1969;1325-43.

79. Rogan S, Radlinger L, Schmidtbleicher D, de Bie RA, de Bruin ED. Preliminary inconclusive results of a randomised double blinded cross-over pilot trial in long-term-care dwelling elderly assessing the feasibility of stochastic resonance whole-body vibration. Eur Rev Aging Phys Activ. 2015;12:5.

80. Thomas JR, Nelson JK, Thomas KT. A generalized rank-order method for nonparametric analysis of data from exercise science: a tutorial. Res Q Exerc Sport. 1999;70(1):11-23.

81. Cohen J. Statistical power analysis for the behavioral sciences. 2nd ed. NJ, USA: Erlbaum, Hillsdale; 1988.

82. Nyman SR, Victor CR. Older people's recruitment, sustained participation, and adherence to falls prevention interventions in institutional settings: a supplement to the Cochrane systematic review. Age Ageing. 2011;40(4):430-6.

83. Zhang L, Weng C, Liu M, Wang Q, Liu L, He Y. Effect of whole-body vibration exercise on mobility, balance ability and general health status in frail elderly patients: a pilot randomized controlled trial. Clin Rehabil. 2014 28(1):59-68

84. Lau RW, Liao LR, Yu F, Teo T, Chung RC, Pang MY. The effects of whole body vibration therapy on bone mineral density and leg muscle strength in older adults: a systematic review and meta-analysis. Clin Rehabil. 2011; 25(11):975-88

85. Rogan S, Hilfiker R. [Training methods - increase muscle strength due to whole-body vibration - force with Hz]. Sportverletz Sportschaden. 2012; 26(4):185-7.

86. Bogaerts A, Delecluse C, Claessens AL, Coudyzer W, Boonen S, Verschueren SM. Impact of whole-body vibration training versus fitness training on muscle strength and muscle mass in older men: a 1-year randomized controlled trial. J Gerontol Ser A Biol Med Sci. 2007;62(6):630-5.

87. Machado A, Garcia-Lopez D, Gonzalez-Gallego J, Garatachea N. Wholebody vibration training increases muscle strength and mass in older women: a randomized-controlled trial. Scand J Med Sci Sports. 2010; 20(2):200-7.

88. Bautmans I, Van Hees E, Lemper JC, Mets T. The feasibility of Whole Body Vibration in institutionalised elderly persons and its influence on muscle performance, balance and mobility: a randomised controlled trial [ISRCTN62535013]. BMC Geriatr. 2005;5:17. 
89. Rogan S, Hilfiker R, Herren K, Radlinger L, de Bruin ED. Effects of whole-body vibration on postural control in elderly: a systematic review and metaanalysis. BMC Geriatr. 2011;11:72.

90. Rogan S, Hilfiker R, Schenk A, Vogler A, Taeymans J: Effects of whole-body vibration with stochastic resonance on balance in persons with balance disability and falls history - a systematic review. Res Sports Med. 2014;22: 294-313.

91. Sitja-Rabert M, Martinez-Zapata MJ, Fort Vanmeerhaeghe A, Rey Abella F, Romero-Rodriguez D, Bonfill X. Effects of a Whole Body Vibration (WBV) Exercise Intervention for Institutionalized Older People: A Randomized, Multicentre, Parallel, Clinical Trial. J Am Med Dir Assoc. 2015;16(2):125-31.

92. Jorgensen MG, Laessoe U, Hendriksen C, Nielsen OB, Aagaard P. Efficacy of Nintendo Wii training on mechanical leg muscle function and postural balance in community-dwelling older adults: a randomized controlled trial. J Gerontol Ser A Biol Med Sci. 2013;68(7):845-52.

93. Wuest $S$, Borghese NA, Pirovano M, Mainetti R, van de Langenberg R, de Bruin ED. Usability and Effects of an Exergame-Based Balance Training Program. Games Health J. 2014;3(2):106-14.

94. De Bruin E, Reith AMD, Murer K. Feasibility of Strength-Balance Training Extended with Computer Game Dancing in Older People; Does it Affect Dual Task Costs of Walking? J Nov Physiother. 2011;1(104).

95. Rogan S, Schmidtbleicher D, Radlinger L: Immediate effects after stochastic resonance whole-body vibration on physical performance on frail elderly for skilling-up training: a blind cross-over randomised pilot study. Aging Clin Exp Res. 2014;26(5):519-27.

96. Sale DG. Neural adaptation to resistance training. Med Sci Sports Exerc. 1988;20(5 Suppl):S135-145.

97. Schmidtbleicher D, Haralambie G. Changes in contractile properties of muscle after strength training in man. Eur J Appl Physiol Occup Physiol. 1981;46(3):221-8.

98. Aagaard P, Simonsen EB, Andersen JL, Magnusson P, Dyhre-Poulsen P. Increased rate of force development and neural drive of human skeletal muscle following resistance training. J Appl Physiol. 2002;93(4):1318-26.

99. Aagaard P. Training-induced changes in neural function. Exerc Sport Sci Rev. 2003:31(2):61-7.

100. Aagard P, Mayer F. Neuronal adaption to strength training. Deutsche Zeitschrift für Sportmedizin. 2007;58(2):50-3.

101. Thorstensson A, Karlsson J, Viitasalo JH, Luhtanen P, Komi PV. Effect of strength training on EMG of human skeletal muscle. Acta Physiol Scand. 1976;98(2):232-6.

102. Bean JF, Leveille SG, Kiely DK, Bandinelli S, Guralnik JM, Ferrucci L. A comparison of leg power and leg strength within the InCHIANTI study: which influences mobility more? J Gerontol Ser A Biol Med Sci. 2003;58(8):728-33.

103. Foldvari M, Clark M, Laviolette LC, Bernstein MA, Kaliton D, Castaneda C, Pu CT, Hausdorff JM, Fielding RA, Singh MA. Association of muscle power with functional status in community-dwelling elderly women. J Gerontol Ser A Biol Med Sci. 2000:55(4):M192-199.

104. Bottaro M, Machado SN, Nogueira W, Scales R, Veloso J. Effect of high versus low-velocity resistance training on muscular fitness and functional performance in older men. Eur J Appl Physiol. 2007;99(3):257-64.

105. Drey M, Zech A, Freiberger E, Bertsch T, Uter W, Sieber CC, Pfeifer K, Bauer $J M$. Effects of strength training versus power training on physical performance in prefrail community-dwelling older adults. Gerontology. 2012;58(3):197-204.

106. Studenski S, Perera S, Wallace D, Chandler JM, Duncan PW, Rooney E, Fox M, Guralnik JM. Physical performance measures in the clinical setting. J Am Geriatr Soc. 2003;51(3):314-22.

107. Penninx BW, Ferrucci L, Leveille SG, Rantanen T, Pahor M, Guralnik JM. Lower extremity performance in nondisabled older persons as a predictor of subsequent hospitalization. J Gerontol Ser A Biol Med Sci. 2000;55(11):M691-697.

108. Ostir GV, Kuo YF, Berges IM, Markides KS, Ottenbacher KJ. Measures of lower body function and risk of mortality over 7 years of follow-up. Am J Epidemiol. 2007:166(5):599-605

109. Investigators LS, Pahor M, Blair SN, Espeland M, Fielding R, Gill TM, Guralnik JM, Hadley EC, King AC, Kritchevsky SB et al. Effects of a physical activity intervention on measures of physical performance: Results of the lifestyle interventions and independence for Elders Pilot (LIFE-P) study. J Gerontol Ser A Biol Med Sci. 2006;61(11):1157-65.

110. Zeyfang A, Braun A. [Guidelines "Diabetes mellitus in the elderly"]. MMW Fortschritte der Medizin. 2009;151(20):33-5. 37
111. Swiss Academy of Medical Sciences. Treatment and care of elderly persons who are in need of care. Swiss Med Wkly. 2004;134(41-42):618-26.

112. Katz S, Ford AB, Moskowitz RW, Jackson BA, Jaffe MW. Studies of Illness in the Aged. The Index of Adl: A Standardized Measure of Biological and Psychosocial Function. JAMA. 1963;185:914-9.

113. Sievanen H, Karinkanta S, Moisio-Vilenius P, Ripsaluoma J. Feasibility of whole-body vibration training in nursing home residents with low physical function: a pilot study. Aging Clin Exp Res. 2014;26(5):511-7.

114. Juni P, Altman DG, Egger M. Systematic reviews in health care: Assessing the quality of controlled clinical trials. BMJ. 2001;323(7303):42-6.

115. Kaptchuk TJ. Effect of interpretive bias on research evidence. BMJ. 2003; 326(7404):1453-5.

116. Chale-Rush A, Guralnik JM, Walkup MP, Miller ME, Rejeski WJ, Katula JA, King AC, Glynn NW, Manini TM, Blair SN et al. Relationship between physical functioning and physical activity in the lifestyle interventions and independence for elders pilot. J Am Geriatr Soc. 2010;58(10):1918-24.

117. Leblanc A, Pescatello LS, Taylor BA, Capizzi JA, Clarkson PM, Michael White C, Thompson PD. Relationships between physical activity and muscular strength among healthy adults across the lifespan. Springer Plus. 2015:4:557.

118. Cress ME, Buchner DM, Questad KA, Esselman PC, deLateur BJ, Schwartz RS. Exercise: effects on physical functional performance in independent older adults. J Gerontol A Biol Sci Med Sci. 1999:54(5):M242-248.

\section{Submit your next manuscript to BioMed Central and we will help you at every step:}

- We accept pre-submission inquiries

- Our selector tool helps you to find the most relevant journal

- We provide round the clock customer support

- Convenient online submission

- Thorough peer review

- Inclusion in PubMed and all major indexing services

- Maximum visibility for your research

Submit your manuscript at www.biomedcentral.com/submit
C Biomed Central 